\title{
Retraction Note to: Investigation on the improvement of physico-mechanical, viscoelastic and morphological properties of isotactic polypropylene (iPP)/ethylene- propylene diene rubber (EPDM)/nitrile rubber (NBR) elastomeric blends
}

\author{
Krishna Dutt Chauhan ${ }^{1} \cdot$ Rakesh Kumar Soni $^{1}$ • \\ Harjeet Singh ${ }^{1}$ \\ Published online: 23 November 2016 \\ (C) Central Institute of Plastics Engineering \& Technology 2016
}

\section{Retraction Note to: Int J Plast Technol (December 2010) 14(2):117-141 DOI 10.1007/s12588-010-0016-0}

"This article is retracted by the Editor-in-Chief as several figures included in this article have been found to have high degrees of similarity with previously published works, viz. "Effect of Dynamic Crosslinking on Impact Strength and Other Mechanical Properties of Polypropylene/Ethylene-Propylene-Diene Rubber Blends" by A. K. Jain, A. K. Nagpal, R. Singhal, Neeraj K. Gupta, Journal of Applied Polymer Science, Vol. 78, 2089-2103 (2000)."

The online version of the original article can be found under doi:10.1007/s12588-010-0016-0.

Krishna Dutt Chauhan

kkdchauhan@gmail.com

1 Department of Chemistry, Ch. Charan Singh University, Meerut, UP 200005, India 